\title{
Implementation of MPPT for PV Isolated System by P\&O, I_C and PSO Methods based on Arduino Technology
}

\author{
Eid A. Gouda, Mohamed. F. Kotb, and Dina A. Elalfy
}

\begin{abstract}
Maximum power point tracking (MPPT) algorithms are very essential for the PV systems since they attract the points of maximum power at any conditions of the varying temperature and irradiation and subsequently decrease the PV array cost. This paper submits a heightened MPPT technique for the PV system using particle swarm optimization (PSO) algorithm comparing with the traditional MPPT methods using perturb and observe (P\&O) and incremental conductance (I_C). MATLAB simulations are carried out under the same irradiation and temperature and a variation in the load and comparing the performance of the three methods. In Protues 8.3 professional software, a design of the proposed model using Arduino UNO of the three algorithms is achieved. One of the important contributions of this paper is the proposed experimental work which is carried out by the combination of Arduino UNO which is coded by $\mathrm{C}$ language and coupled with MATLAB results which obtained by the simulation for the used different optimization methods in this paper. At the end of this paper, there is a comparison in tabular form between the presented 3 optimization methods with their experimental results. It is found that the results obtained by using PSO are more acceptable.

The main advantages of the PSO are as follows: - it reduces the oscillations at the steady state (to approximately zero) once the MPP is located, and its algorithm is very fast comparing to the other two methods.
\end{abstract}

Index Terms-Maximum Power Point Tracking (M.P.P.T);Photovoltaic system PV; incremental conductance (I_C); Arduino UNO; Perturb \&Observe (P\&O); particle swarm optimization (PSO)

\section{INTRODUCTION}

Thinking of the future source of energy, definitely solar energy the most promising source [1]. It can be easily achieving needed electrical power from PV system by coupling the modules in parallel or in series. The most popular technique or algorithm used in PV production system is "Maximum Power Point Tracking" (MPPT). This technique allows getting maximum power that the module can give and track it over time. The MPPT technique can be adapted to improve and optimize the performance of the PV modules. The expected efficiency by using this technique could be improved by $25 \%$ [2]. In this paper, the PSO method is introduced and compared with the conventional MPPT methods using I_C and P\&O. The proposed model is simulated using MATLAB software [3] and it is designed using Protues 8.3 professional software. The experimental work is done using a standalone PV Module comprises three identical solar modules coupled in series and it is tested using the three algorithms.

In this paper, the description of the proposed model is discussed in section II after that the Simulation and experimental work results are mentioned in section III.

\section{THE DESCRIPTION OF THE PROPOSED MODEL.}

In figure. 1, it's shown the circuit diagram of the PV module with The MPPT controller. The main components of the model are: PV panel, current sensor, voltage sensor, buck converter, MOSFET driver, MPPT controller and the load. The full description of each element is provided in details in the following sections.

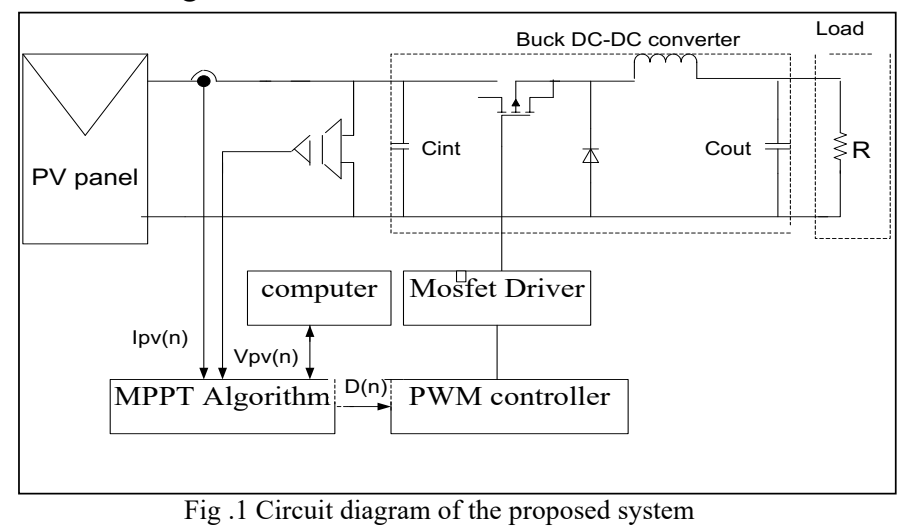

\section{A. A. The PV System}

\section{B. 1. Mathematical Model of the photovoltaic Module}

The PV simple equivalent circuit contains the next basic components; current source, series resistor, diode and shunt resistor as displayed in Fig.2. [4, 5].

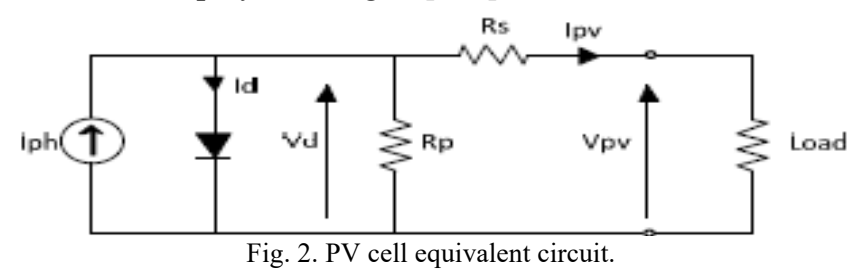

The load current $\left(\mathrm{I}_{\mathrm{pv}}\right)$ is the difference of the photo current and the normal diode current obtained by applying Kirchoffs current law as follows: 


$$
\begin{aligned}
& I_{p v}=I_{p h}-I_{d}-I_{p} \\
& I_{p v}=I_{p h}-I_{o}\left(e^{\frac{v_{p v}+R_{s} I_{p v}}{v_{t} Q_{d} n_{s}}}-1\right)-\frac{v_{p v}+R_{s} I_{p v}}{R_{p}}
\end{aligned}
$$

Where:

$\mathrm{v}_{\mathrm{pv}}=$ module voltage $(\mathrm{V})$,

$\mathrm{I}_{\mathrm{pv}}=$ module current $(\mathrm{A})$,

$\mathrm{I}_{\mathrm{ph}}=$ photocurrent $(\mathrm{A})$,

$\mathrm{I}_{\mathrm{o}}=$ reverse saturation current $(\mathrm{A})$

$\mathrm{q}=$ the electronic charge

$\mathrm{Q}_{\mathrm{d}}=$ diode factor,

$\mathrm{n}_{\mathrm{s}}=$ number of cells in series,

$\mathrm{R}_{\mathrm{s}}=$ series resistor $(\Omega)$,

$\mathrm{R}_{\mathrm{p}}=$ shunt resistor $(\Omega)$

$\mathrm{K}=$ Boltzmann's constant,

$\mathrm{T}=$ absolute temperature $(\mathrm{K})$, and

$\mathrm{v}_{\mathrm{t}}=\mathrm{kT} / \mathrm{q}$ is thermal voltage $(\mathrm{V})$,

The proposed experimental study in this paper includes three identical solar modules which are coupled in series. The used PV module parameters at standard test condition (STC) are tabulated in Table I.

The Matlab software is used to model the used system depending on the previous equations.

The characteristics curves for the used PV array are shown in Fig.3.

TABLE (I): Electrical parameters for a single PV module at STC.

\begin{tabular}{ll}
\hline \hline Item & Data \\
\hline Maximum Power & $10 \mathrm{~W}$ \\
Voltage at maximum power & $6 \mathrm{~V}$ \\
Current at maximum power & $1.66 \mathrm{~A}$ \\
Cells per module & 12 \\
Cell Dimension $(\mathrm{mm})$ & $30 * 156$ \\
Glass Dimension $(\mathrm{mm})$ & $244 * 344$ \\
Cell Temperature in Kelvin & 298 \\
\hline \hline
\end{tabular}

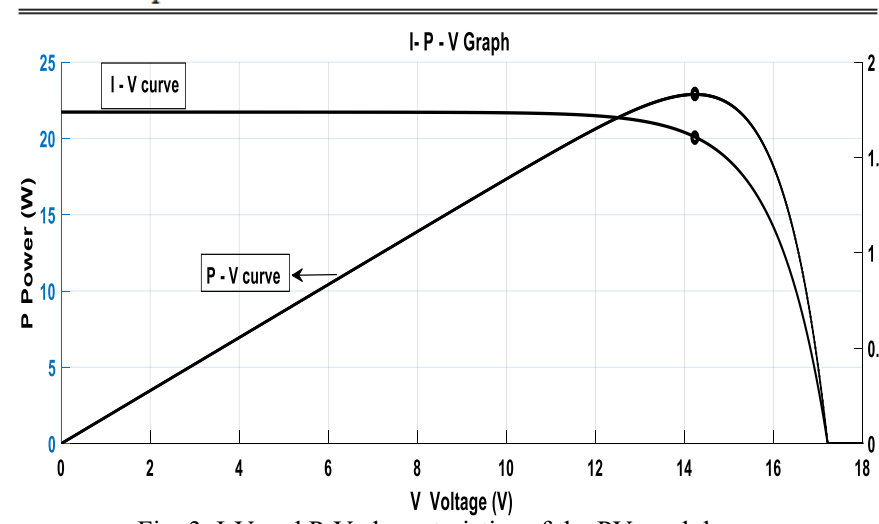

Fig .3. I-V and P-V characteristics of the PV module

\section{B. Current sensor}

It is used to measure the PV current and convert it simultaneously to a suitable analog voltage signal between $(0-5 \mathrm{~V})$. The obtained signal is fed to the analog input (Pin_A0) of the used Arduino Uno ATmega328P (Fig.8). Then it converted to the corresponding decimal number generally between (0-1023bits). The figure of the used current sensor is shown below [6].

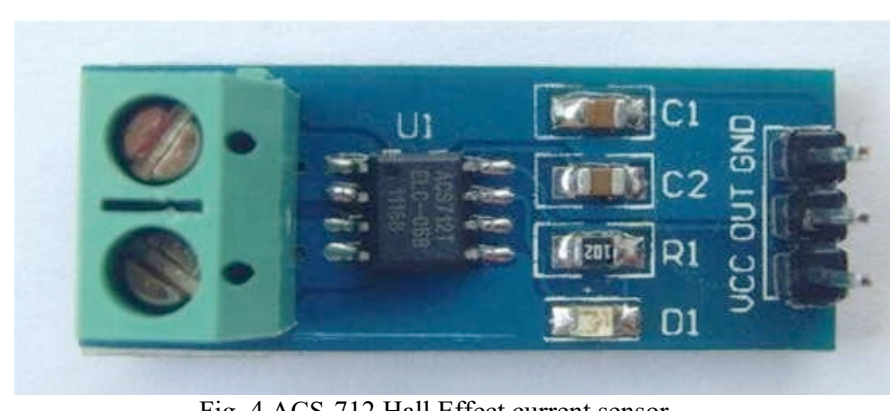

Fig. 4 ACS-712 Hall Effect current sensor

\section{C. Voltage sensor}

On account of Arduino cannot read the value of the voltage greater than $5 \mathrm{~V}$, therefore the voltage divider is used to reduce the PV voltage to a lower one between $(0-5 \mathrm{~V})$. The Arduino board receives the analog voltage input from the voltage sensor and then converts it to a digital signal. The circuit of the voltage divider is presented in fig. 5 .

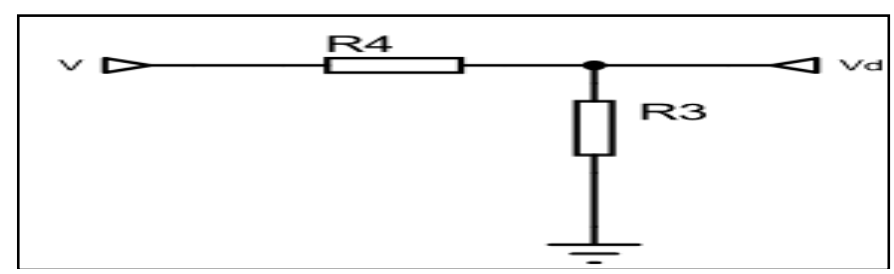

Fig.5. Voltage divider circuit

\section{D. Buck converter}

It is used to reduce efficiently the voltage value from one value to another. As shown in fig (6), it can be seen that the buck converter comprise MOSFET switches, a diode and an inductor are the elements of the buck converter also there are capacitors at the input and output sides [7]. To filter the input current pulses and the output voltage, the input capacitor and the output capacitor are used. The component values for the buck converter are tabulated in Table II.

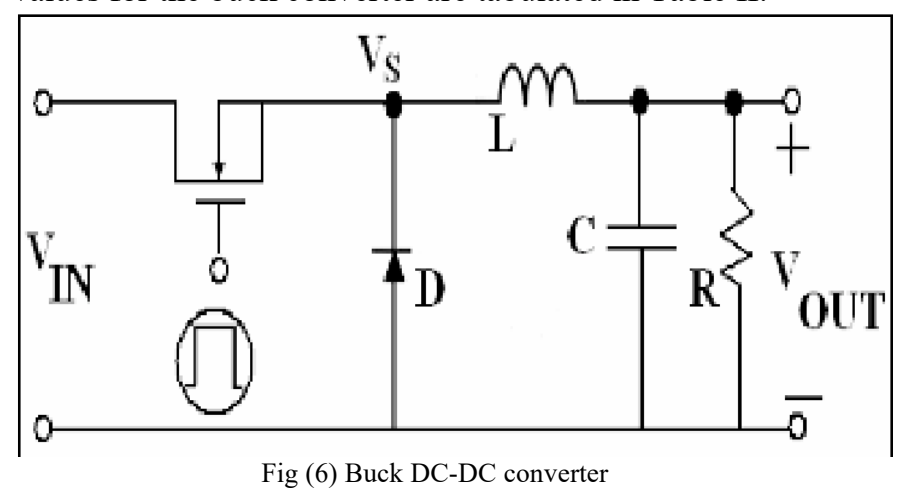

TABLE II. THE VALUES OF THE COMPONENTS OF THE BUCK CONVERTER

\begin{tabular}{ll}
\hline \hline Component & Value \\
\hline Switching Frequency & $31.2 \mathrm{KHZ}$ \\
Inductor, L & $150 \mathrm{H} / 5 \mathrm{~A}$ \\
Capacitors. C & $C_{\text {in }}=33 \mathrm{UF} / 50 \mathrm{~V}$ \\
& $C_{\text {out }}=100 \mathrm{UF} / 16 \mathrm{~V}$ \\
Diode & $1 \mathrm{n} 4148$ \\
MOSFET switch & IRF3205(55v/110
\end{tabular}




\section{E. E. MOSFET driver}

The voltage coming from the Arduino microcontroller output (Pin_A10) is not enough to run the MOSFET as its current is inadequate to charge the capacitor in the MOSFET circuit. This is why IR2112 half bridge IC driver is used to enlarge the voltage value from $(3.3-5 \mathrm{~V})$ to $(10.5-12 \mathrm{~V})$ [8]. In Fig. 7, the circuit of the IR2112 MOSFET driver is shown.

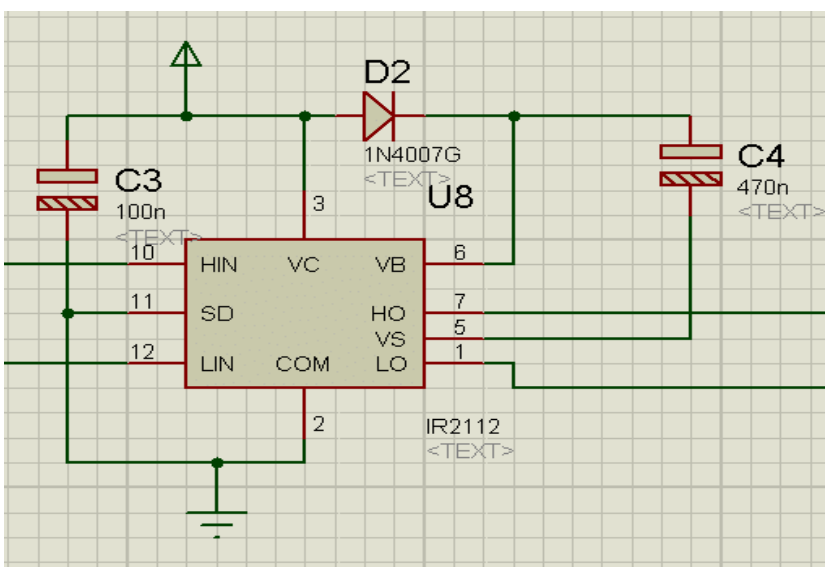

Fig. 7. Typical connection of MOSFET driver [8]

\section{F. F. Arduino as microcontroller}

Based on an ATmega328P microcontroller, the Arduino UNO board is developed and used in this paper [9]. This microcontroller controls all the functions of the tracker, and runs ADCs and DACs that handle the analog section, calculating the power point of the array. This board is very easy to be used as it contains all that is required to sustain the microcontroller USB or power cable with AC to DC adapter or battery can easily start the Arduino board [10].

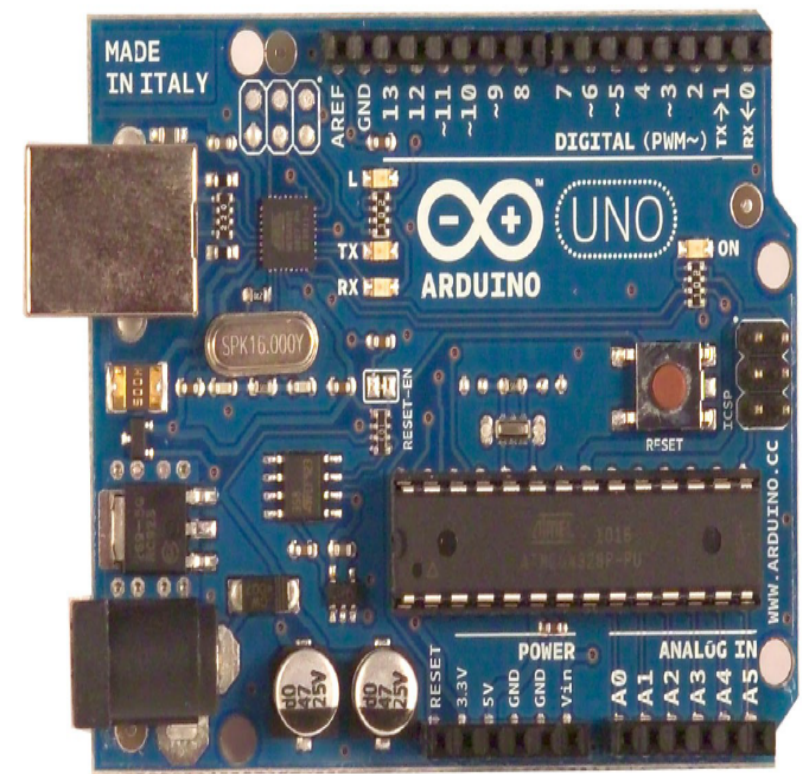

Fig. 8 Arduino UNO Board
TABLE III SPECIFICATIONS OF ARDUINO UNO BOARD BASED ATMEGA328P [10].

\begin{tabular}{ll}
\hline \hline Microcontroller & \multicolumn{1}{c}{ Value } \\
\hline Operating Voltage & $5 \mathrm{~V}$ \\
Input Voltage (recommended) & $7-12 \mathrm{~V}$ \\
Input Voltage(limit) & $6-20 \mathrm{~V}$ \\
Digital I/O Pins & 14 \\
PWM Digital I/O Pins & 6 \\
Analog Input Pins & 6 \\
DC Current per I/O Pin & $20 \mathrm{~mA}$ \\
DC Current for 3.3V Pin & $50 \mathrm{~mA}$ \\
Flash Memory & $32 \mathrm{kB}$ \\
SRAM & $2 \mathrm{kB}$ \\
EEPROM & $1 \mathrm{kB}$ \\
Clock Speed & $16 \mathrm{MHz}$ \\
LED_BUILTIN & 13 \\
Width & $53.4 \mathrm{~mm}$ \\
Weight & $25 \mathrm{~g}$ \\
Length & $68.6 \mathrm{~mm}$ \\
\hline \hline
\end{tabular}

\section{G. G. Maximum power point tracker techniques}

In this paper, there are three algorithms that used to get the maximum power from the PV module: P\&O which introduced in [11], I_C developed in [12] and PSO presented in $[13,14]$.

Also, the programmed Arduino UNO Microcontroller is used as a MPPT algorithm and PWM controller which allow us to control the PWM signal which responsible for controlling the buck converter. From the MPPT algorithm, The output PWM signal is a square waveform of maximum amplitude $5 \mathrm{~V}$, constant frequency of $31.2 \mathrm{kHz}$, and variable duty cycle $D(0 \%-100 \%)$. The Mosfet driver is responsible for transfer the PWM signal to the MOSFET switches of the buck converter.

\section{III. SIMULATION AND EXPERIMENTAL RESULTS}

\section{A. A. Simulation using MATLAB}

The PV module is simulated by MATLAB utilizing the three MPPT methods (P\&O, I_C and PSO) under constant irradiation at $1000 \mathrm{~W} / \mathrm{m}^{2}$, cell temperature at $25{ }^{\circ} \mathrm{c}$ and variable load conditions.

\section{B. 1. Simulation results using $P \& O$ method}

The PV model and the P\&O MPPT algorithm are simulated using MATLAB under constant irradiance at 1000 $\mathrm{W} / \mathrm{m}^{2}$, cell temperature at $25^{\circ} \mathrm{c}$ and the resistance of the load is boosted from 5 ' $\Omega$ to $9 \Omega$ at time equal $1.3 \mathrm{~s}$. At this moment, the operating point will move to the right direction of the $p-v$ curve fig. 9 and the power will decrease from 24 $\mathrm{w}$ to $16 \mathrm{w}$ because of the lowering in current and boosting in voltage as shown in Fig.10. At this moment, the P\&O MPPT algorithm try to return the PV module to operate at the MPP by increasing the duty cycle.

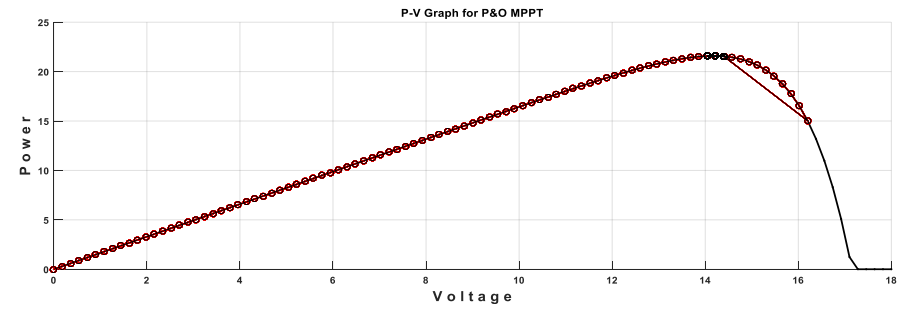


Fig. 9. P-V curve for $\mathrm{P} \& \mathrm{O}$ method
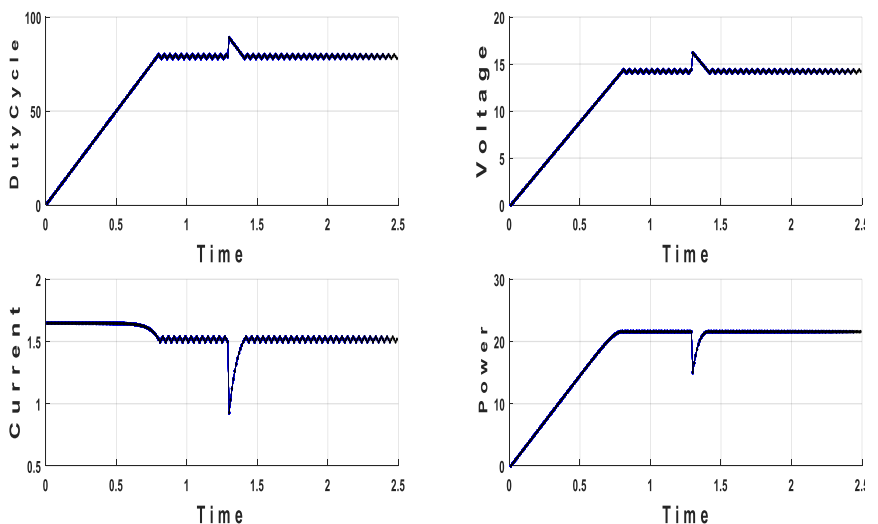

Fig. 10. Power, current, voltage and duty cycle under implementation of P\&O method.

\section{Simulation results using I_C method}

The used algorithm in this section is I C algorithm and as it was done for $\mathrm{P} \& \mathrm{O}$ method, the load is heightened from 5 ' $\Omega$ to 9 ' $\Omega$ under constant irradiation at $1000 \mathrm{~W} / \mathrm{m}^{2}$ and cell temperature at $25^{\circ} \mathrm{c}$.

The P-V curve and (the duty cycle, voltage, current and power) under implementation of I_C method are presented in figs. 11 and 12 .

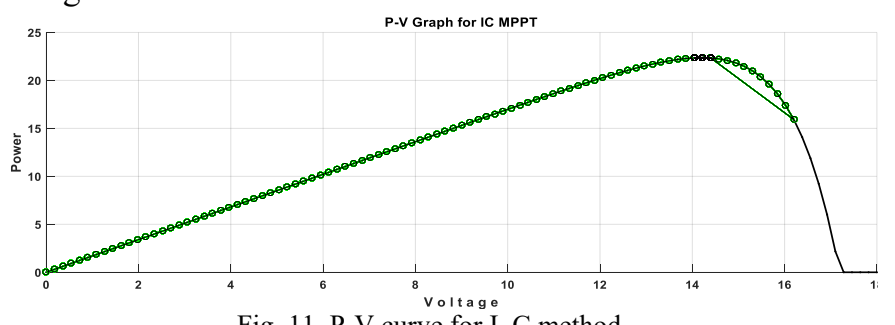

Fig. 11. P-V curve for I_C method
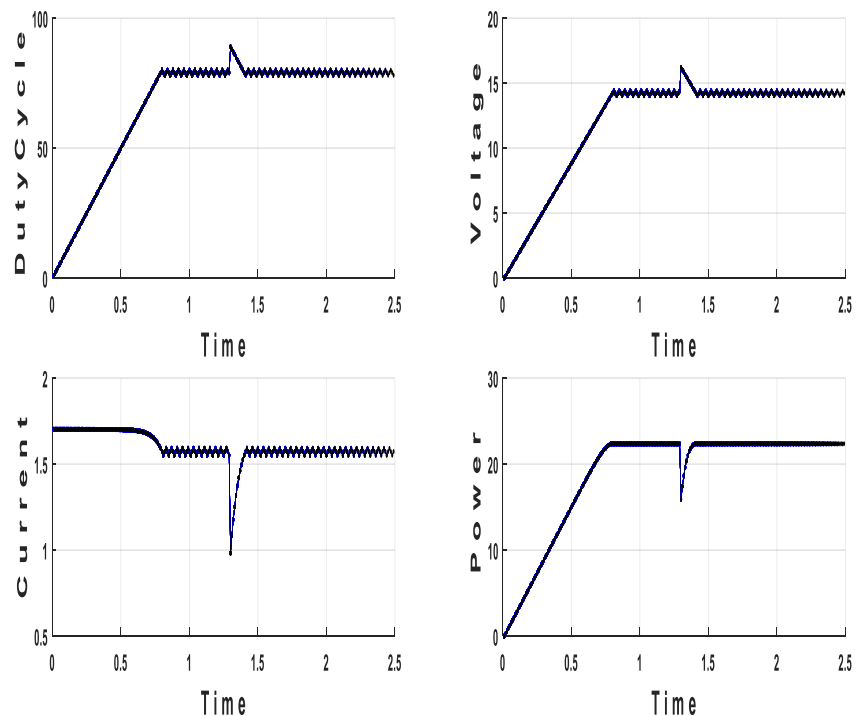

Fig. 12. Power, current, voltage and duty cycle under implementation of I_C method.

\section{3. Simulation results using PSO method}

In this section, the PSO algorithm is used to obtain the MPP and the parameters of this algorithm are included in table (IV).

TABLE IV PARAMETERS USED FOR PSO ALGORITHM

\begin{tabular}{cc}
\hline PARAMITERS & VALUE \\
\hline NO OF PARTICLES $(\mathrm{N})$ & 100 \\
\hline NO OF DIMENSIONS $(\mathrm{D})$ & 1 \\
\hline MAXIMUM VELOCITY $\left(V_{\text {max }}\right)$ & 4 \\
\hline NO OF ITERATIONS $\left(\right.$ Iter $\left._{\text {max }}\right)$ & 250 \\
\hline ACCELERATION CONSTANT 1 $\left(c_{1}\right)$ & 1.2 \\
\hline ACCELERATION CONSTANT $2\left(c_{2}\right)$ & 1.8 \\
\hline INITIAL INERTIA WEIGHT $\left(w_{1}\right)$ & 0.5 \\
\hline FINAL INERTIA WEIGHT $\left(w_{2}\right)$ & 0.7 \\
\hline
\end{tabular}

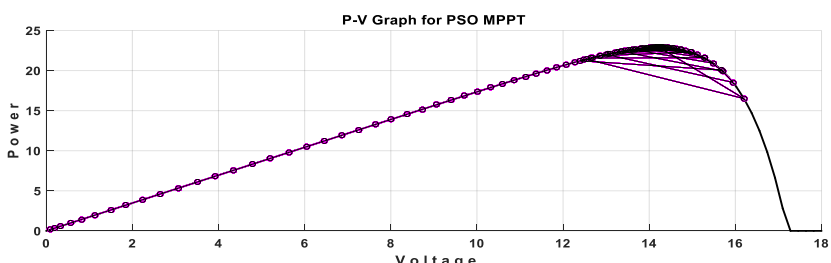

Fig. 13. P-V curve for PSO method
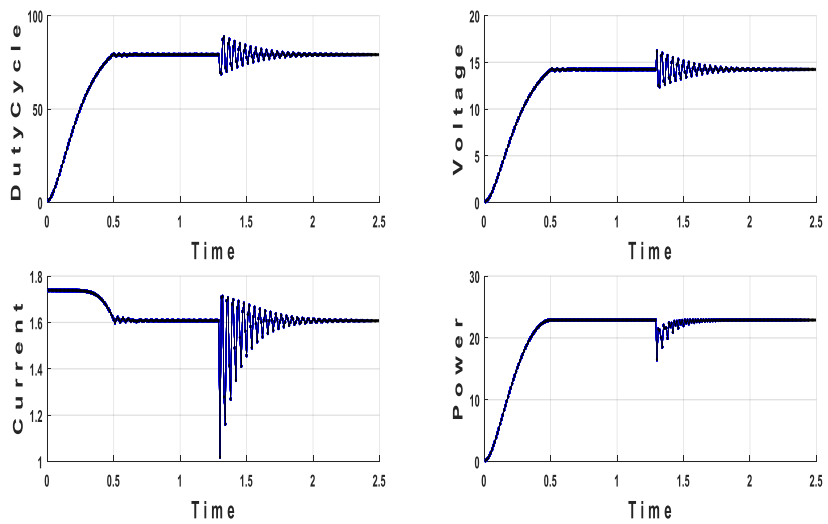

Fig. 14. Power, current, voltage and duty cycle under implementation of PSO method.

It's cleared from figure (15) that the power delivered from the model that uses PSO controller is larger than the power from the same model using I_C and P\&O controller. It is also observed that PSO is faster than other two methods and more stable in the steady state.
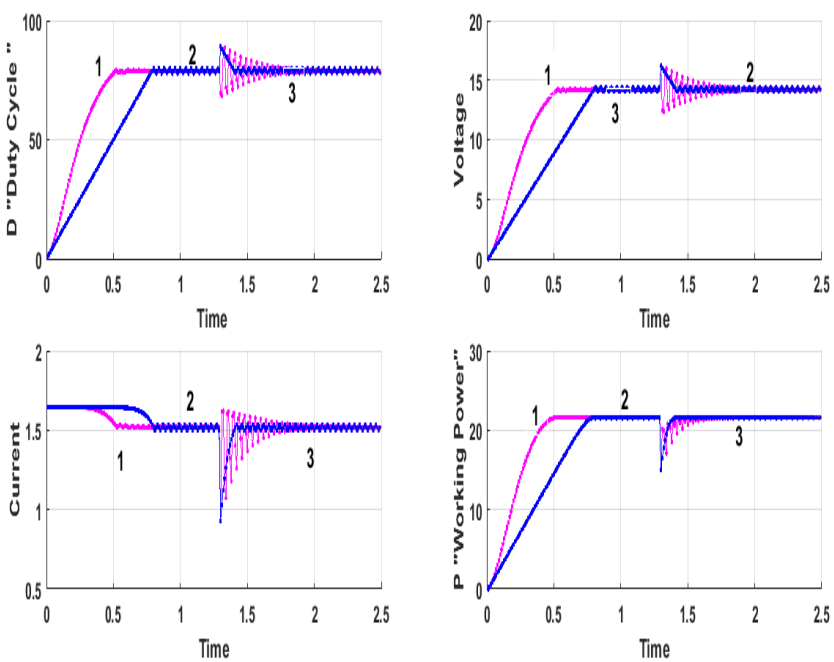

Fig. 15. Power, current, voltage and duty cycle for the three methods (1)PSO, (2)I_C and (3) P\&O.

\section{B. Simulation with Proteus}

The first step of using Proteus for implementation the three methods is to model a PV module in Proteus tool as shown in Fig. 16. 
Figs. 17, 18 present the I-V and P-V characteristics for PV panel by using Proteus.

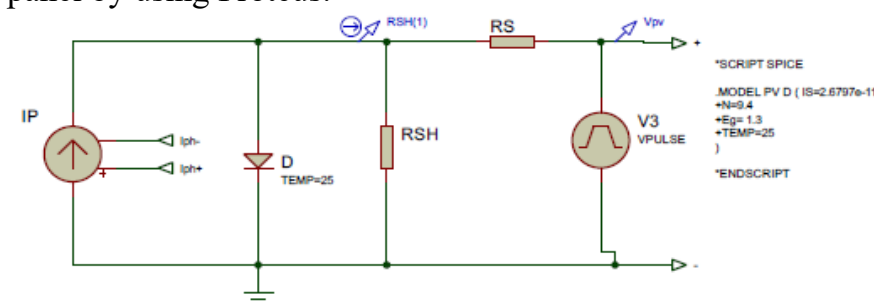

Fig. $1 \overline{6}$. The PV panel model under Proteus

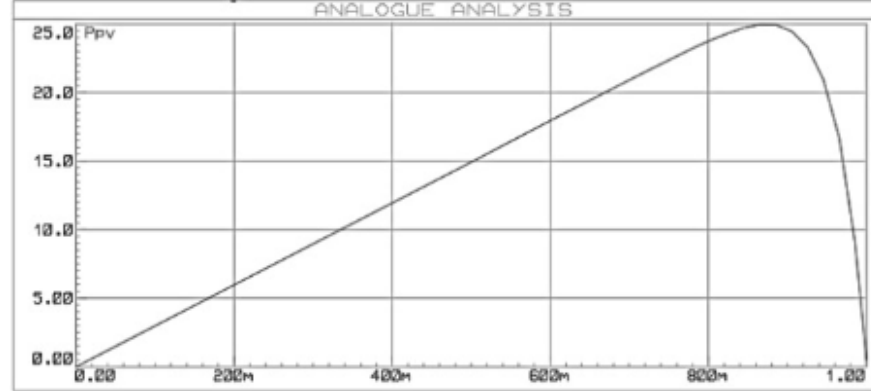

Fig. 17. P-V characteristics for PV panel by using Proteus

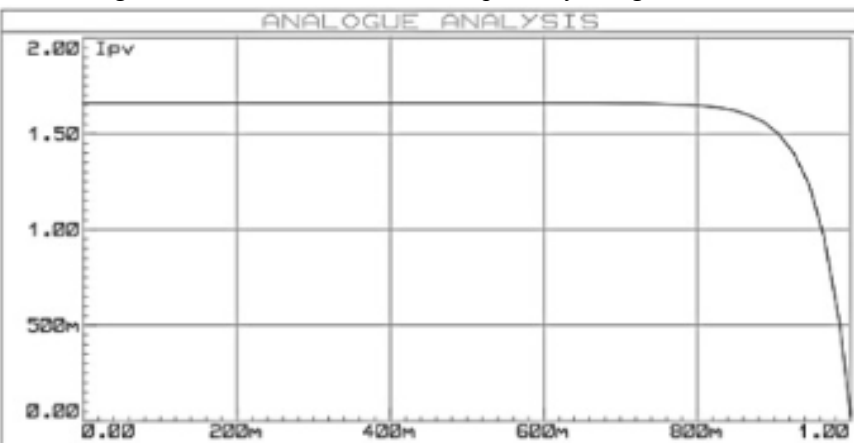

Fig. 18. I-V and P-V characteristics for PV panel by using Proteus

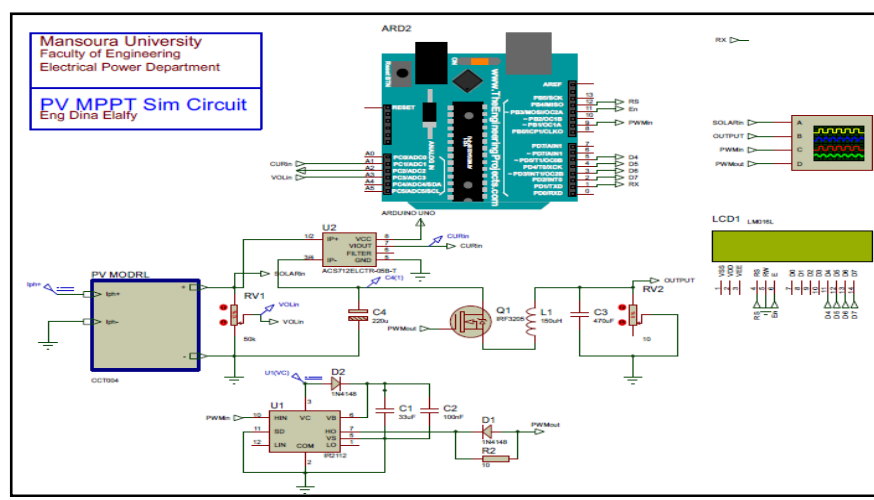

Fig. 19. The proposed model Using Arduino and Proteus

As shown in fig. 19, the proposed model comprises a PV panel, DC-DC buck converter, current sensor, voltage sensor, Arduino board and load. The voltage and current of the module taken from voltage and current sensors are required for Arduino board to calculate PV power. And then, the PV voltage, current, power and duty cycle are displayed on the LCD screen.

\section{E. 2.1 Results from Proteus}

The duty cycle, current, voltage and extracted power from PV module for the used methods (P\&O, I_C and PSO) are shown in figs. 20, 21 and 22.

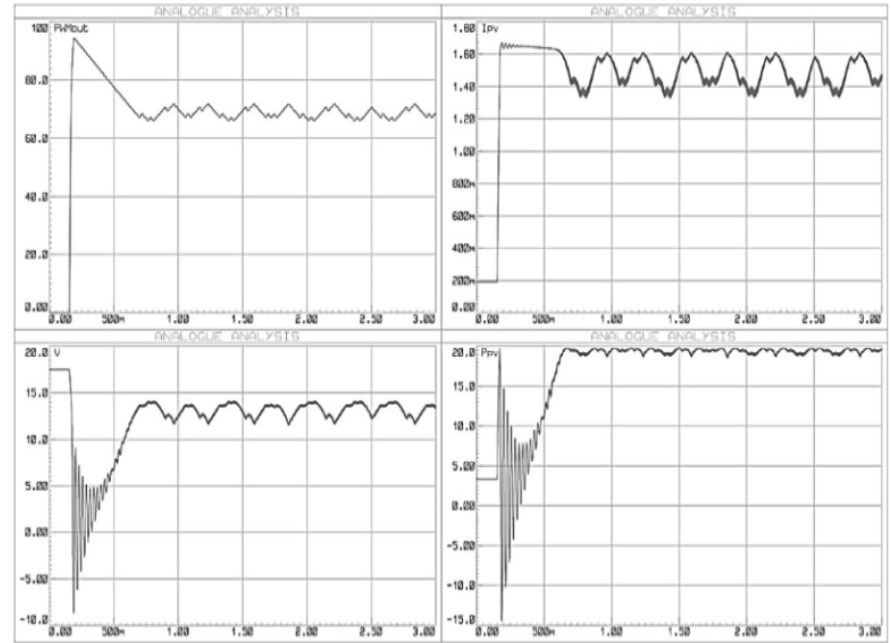

Fig. 20.The results for $\mathrm{P} \& \mathrm{O}$ method using Proteus

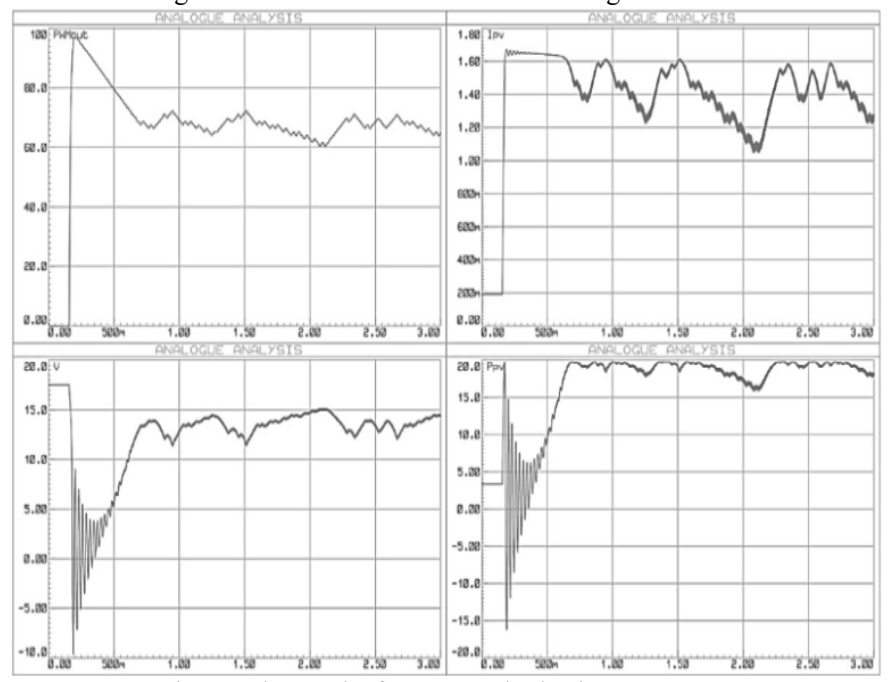

Fig. 21.The results for I C method using Proteus

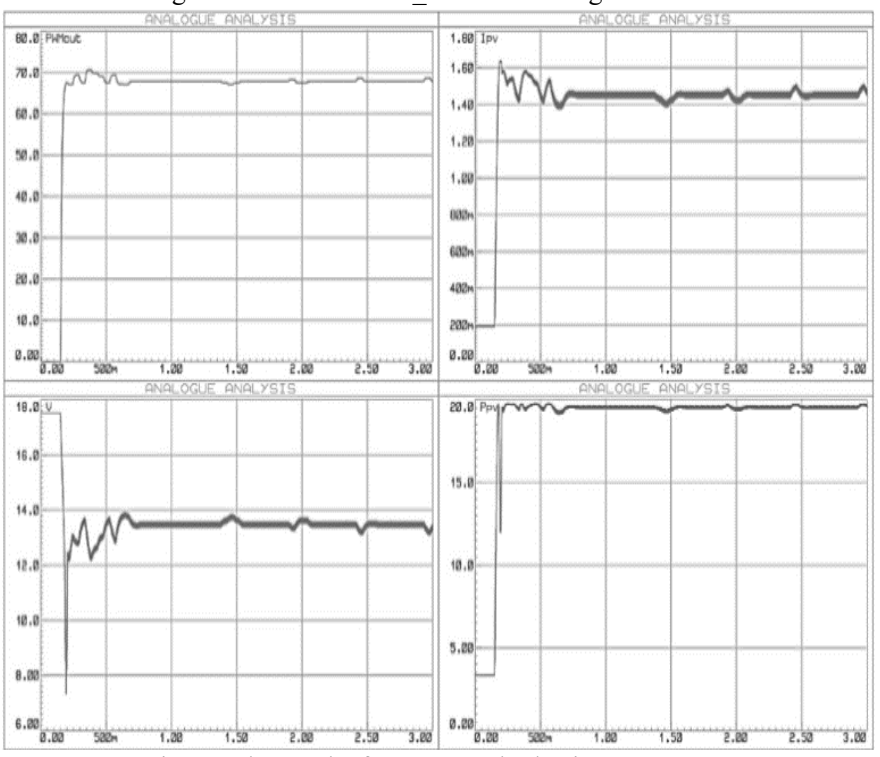

Fig. 22.The results for PSO method using Proteus

\section{F. C. Experimental work}

The Arduino microcontroller is the programmed board used to implement the entire system using the algorithms of P\&O, I C and PSO methods. In figs. 23, 24 and 25, the implement breadboard, the printed circuit board and the proposed model are presented. 


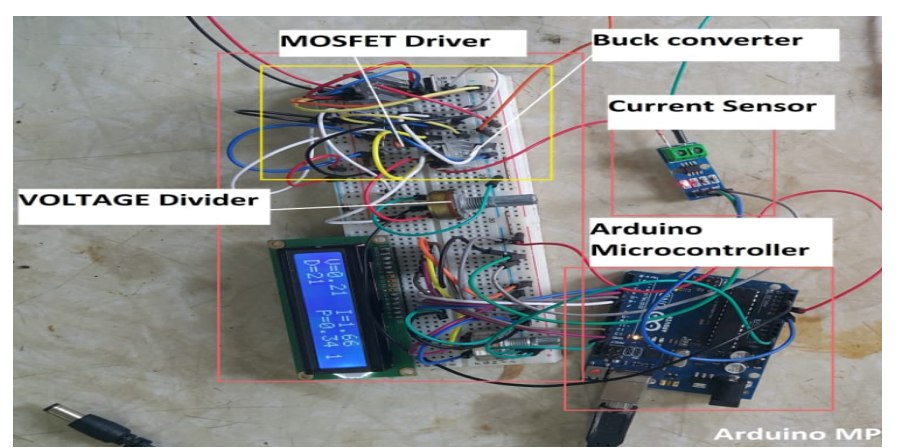

Fig (23) breadboard configuration.
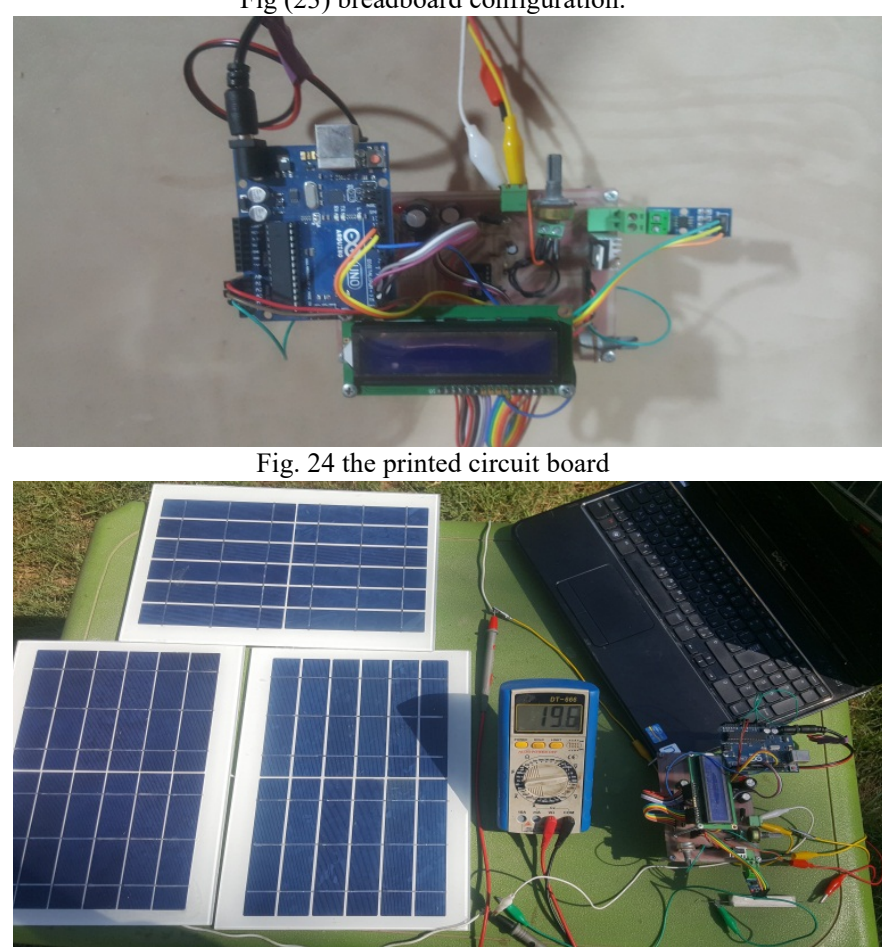

Fig. 25 the proposed model.

1. experimental results for the three methods

After preparing the Arduino UNO board by uploading the used MPPT codes on it (one at a time), with the resistive load varies from 5 ' $\Omega$ to 9 ' $\Omega$ at $1.3 \mathrm{~s}$ and the duty cycle varies from $(0$ to $100 \%)$.
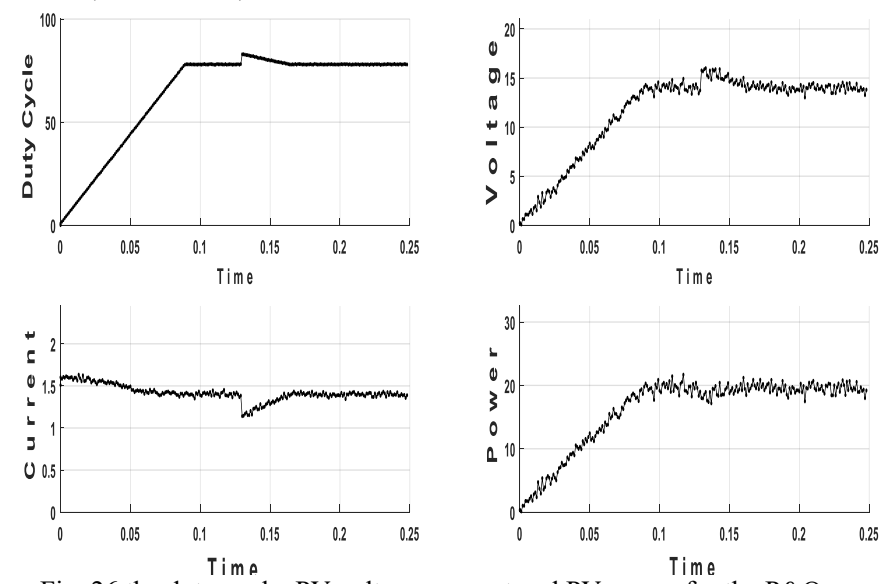

Fig. 26 the duty cycle, PV voltage, current and PV power for the P\&O method.

When the load is increased at time $1.3 \mathrm{~s}$, the PV power will decrease due to the lowering in current and the boosting in voltage and the MPPT algorithm tries to return the PV module to operate at the MPP by increasing the duty cycle.

The duty cycle, PV voltage, current and PV power for the P\&O, I_C and PSO methods are presented in Figs. 26, 27 and 28 .
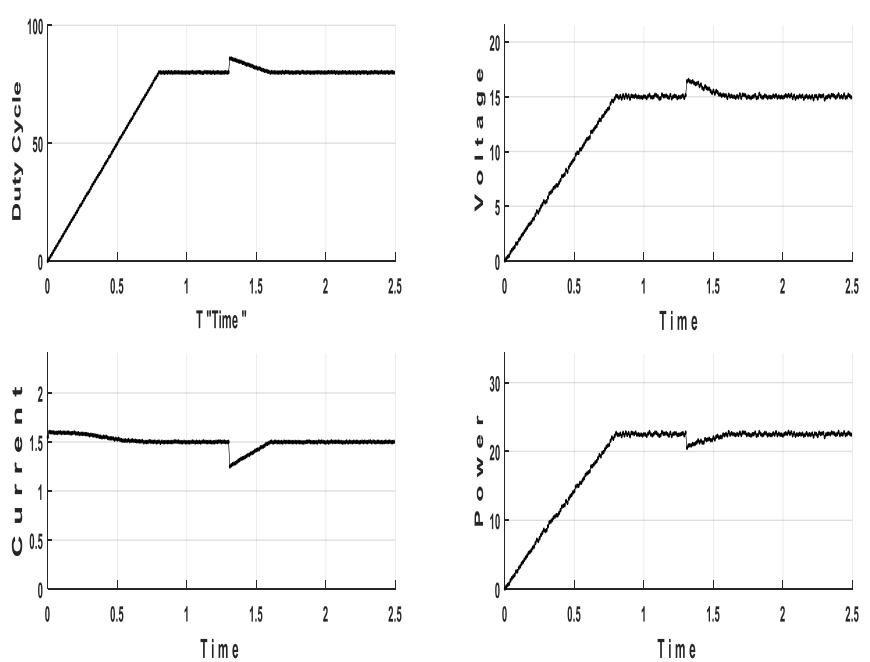

Fig. 27.the duty cycle, PV voltage, current and PV power for the I_C
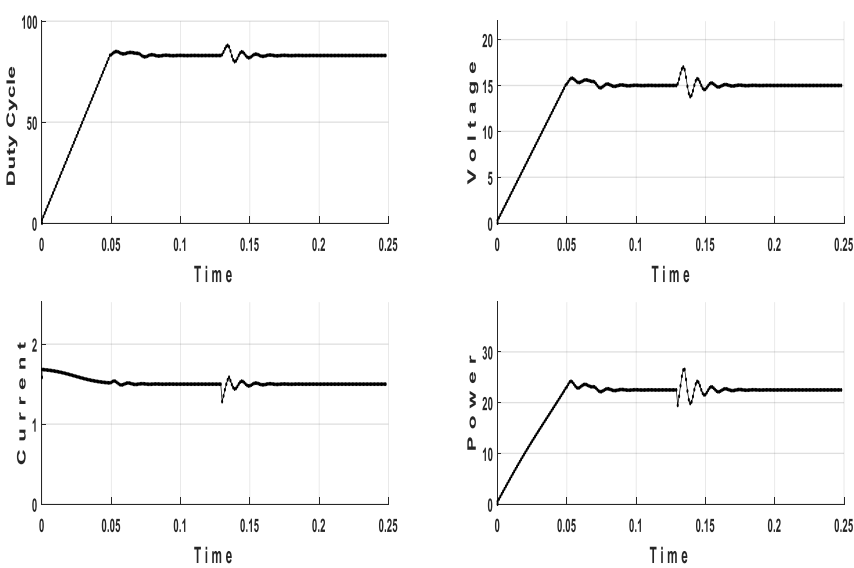

Fig. 28.the duty cycle, PV voltage, current and PV power for the PSO

\section{G. 2. Comparison between experimental results}

As it cleared from fig. 29, that PSO algorithm is faster than I_C and P\&O to obtain the MPP, the steady state oscillations are almost zero when using PSO. For the P\&O method, the oscillations are high and as a result, there will be more power losses than I_C and PSO.
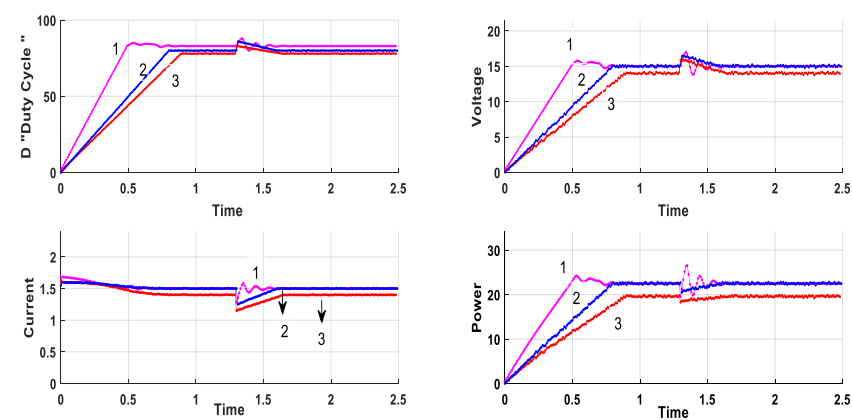

Fig. 29.The duty cycle, PV voltage, current and PV power for the three methods (1)PSO, (2)I_C and (3) P\&O

The table $\mathrm{V}$ totalizes the performance comparison between the three methods through several factors: the tracked power, power losses, time taken to obtain MPP and effeciency. The time taken to reach MPP is commensurate with the tracking speed.

The MPPT effeciency is calculated by using this equation.

MPPT effeciency $(\%)=\frac{p_{\text {out }}(\text { tracked })}{p_{\text {max }}(\text { rated })} * 100 \%$ 
TABLE V. COMPARISON BETWEEN PSO, I C AND P\&O ALGORITHMS

\begin{tabular}{llll}
\hline \hline & \multicolumn{3}{c}{ Method } \\
\cline { 2 - 4 } Parameter & PSO & I_C & P\&O \\
\hline $\begin{array}{c}\text { Tracked power (w) } \\
\text { Process time to } \\
\text { reach MPP (s) }\end{array}$ & 23.1 & 22.5 & 22 \\
$\quad 0.5$ & 0.8 & 0.89 \\
$\begin{array}{c}\text { Power loss (w) } \\
\text { MPPT effeciency }\end{array}$ & 1 & 1.6 & 2.1 \\
$(\%)$ & 95.85 & 93.36 & 91.28 \\
\hline \hline
\end{tabular}

It is spotted that PSO has the highest efficiency, least power losses and the highest precision than P\&O and I_C. Plus, PSO has larger tracking speed than I C and P\&O with the least time in between the other two methods (the tracking speed is proportional to the time taken to get the MPP).

\section{VI. CONCLUSION}

The three techniques P\&O, I_C and PSO are used to simulate and model a PV system relied on MPPT. The algorithms are simulated and tested using MATLAB software and Proteus tool. This paper presents an experimental work to model a PV system anchored in MPPT using the three algorithms and a comparison between the experimental results based on the tracked power, tracking speed, power loss and efficiency.

The comparison showed that PSO has higher tracked power, higher tracking speed, lower power loss and higher efficiency than the two other methods.

\section{REFERENCES}

[1] Mihir Pathare, Vimith Shetty, " Designing and Implementation of Maximum Power Point Tracking (MPPT) Solar Charge Controller", 2017 International Conference on Nascent Technologies in the Engineering Field.

[2] Haithem Chaieb , Anis SAKLY," Comparison between P\&O and P.S.O Methods Based MPPT Algorithm for Photovoltaic Systems", 16th international conference on Sciences and Techniques of Automatic control\& computer engineering - STA'2015, Monastir, Tunisia, December 21-23, 2015.

[3] Matlab, Global Optimization Toolbox, "User's Guide (R2015b)," The MathWorks Inc., 2016.

[4] TarakSalmi*, MounirBouzguenda**, Adel Gastli**, Ahmed Masmoudi*, "MATLAB/Simulink Based Modelling of Solar Photovoltaic Cell", INTERNATIONAL JOURNAL of RENEWABLE NERGY RESEARCH TarakSalmi et al., Vol.2, No.2, 2012.

[5] Giovanni Celsa, Giuseppe Marco Tina, "Matlab/Simulink Model of Photovoltaic Modules/Strings under Uneven Distribution of Irradiance and Temperature", 2015 6th International Renewable Energy Congress (IREC).

[6] Ananya Dutta, Niloy Barua, Aninda Saha," Design of an Arduino based Maximum Power Point Tracking (MPPT) Solar Charge Controller", A Thesis Submitted to the Department of Electrical and Electronic Engineering, BRAC University.

[7] M. Wens and M. Steyaert, Design and implementation of fullyintegrated inductive DC-DC converters in standard CMOS, Dordrecht: Springer Netherlands, 2011.

[8] [Online]. Available: www.datasheetcatalog.com /IR2112 datasheet.

[9] [Online]. Available: http://www.arduino.cc/

[10] Ammar AL-GIZI, Mohammed AL-SAADI, Sarab AL-CHLAIHAWI, "Experimental Installation of Photovoltaic MPPT Controller Using Arduino Board", IEEE, 2018.
[11] Arvind Kumar, Manoj Kumar, Dattatraya H. Nagaraj, Amanpreet Singh, JayanthiPrattapati, "Implementation of MPPT Algorithm for Grid Connected PV Module with IC and P\&O Method",International Journal of Electrical, Computer, Energetic, Electronic and Communication Engineering Vol:8, No:7, 2014.

[12] Jay Patel1, Vishal sheth2, Gaurang Sharma3, "Design \& simulation of photovoltaic system using incremental MPPT algorithm" International Journal of Advanced Research in Electrical, Electronics and Instrumentation Engineering Vol. 2, Issue 5, May 2013.

[13]U. Rai1, "Modeling of Solar PV system under Partial Shading using Particle Swarm Optimization based MPPT," International Research Journal of Engineering and Technology (IRJET), Feb 2017.

[14] O. B. Belghith, L. Sbita and F. Bettaher, "MPPT Design Using PSO Technique for Photovoltaic System Control Comparing to Fuzzy Logic and P\&O Controllers" ,Energy and Power Engineering, 2016.

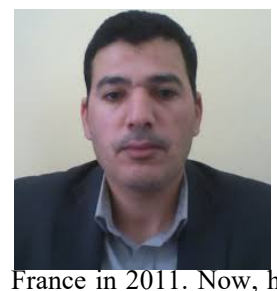

Eid Abdelbaki GOUDA was born in Domiatta, Egypt, on 1975. He received B.Sc. And M.Sc. Degree from electrical engineering Mansoura University in 1997 and 2004 respectively. He is completed his Ph.D at University Henri Poincaré of Nancy, the Groupe de Recherche en Electrotechnique et Electronique de Nancy, faculty of Engineering, Mansoura University. He is interested in Magnetic Gear, Electric Machine Design/Control and Protection Systems. His E mails are: eid.gouda@yahoo.fr and eaidgoda@mans,edu.eg.

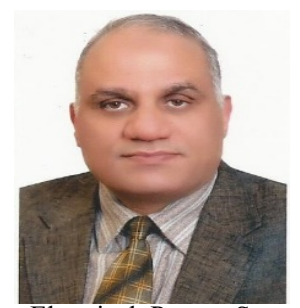

Mohamed F. Kotb was born in Monofia, Egypt, on 1960. He graduated from Mansoura University, faculty of Engineering, power and machine department. He received M.Sc. and PhD Degree from Mansoura University in 1989 and 1998 respectively. $\mathrm{He}$ is a member of Electrical Department in faculty of Engineering, Mansoura University. He is interested in The Electrical Power System Analyses and application researches. He has wide experience with industry applications, consultations and International Training. Dr. Mohamed is member in IEEE. His E mail is: mohamadfawzi@gmail.com. 